\title{
EFFICACY OF PECTORAL NERVE BLOCK TYPE II VERSUS THORACIC PARAVERTEBRAL BLOCK FOR ANALGESIA IN BREAST CANCER SURGERY
}

DOl: 10.36740/WLek202007129

\author{
Volodymyr V. Martsiniv ${ }^{1,2}$, Oleg A. Loskutov ${ }^{1}$, Andriy M. Strokan ${ }^{1,2}$, Mihaylo V. Bondar ${ }^{1}$ \\ 'SHUPYK NATIONAL MEDICAL ACADEMY OF POSTGRADUATE EDUCATION, KYIV, UKRAINE \\ 2FEOFANIYA CLINICAL HOSPITAL OF STATE MANAGEMENT OF AFFAIRS, KYIV, UKRAINE
}

\begin{abstract}
The aim: to compare the efficacy of pectoral nerve block type II and thoracic paravertebral block for analgesia during and after breast cancer surgery.

Materials and methods: Sixty adult women were undergoing unilateral radical mastectomy or quadrantectomy with axillary dissection. Patients were randomized to receive either pectoral nerve block with ropivacaine $0.375 \% 30 \mathrm{ml}$ or thoracic paravertebral block with ropivacaine $0.5 \% 20 \mathrm{ml}$. Evaluated variables included pain intensity at $0,2,4,6$, 12, 18 and 24 hours, intraoperative fentanyl, 24-hour postoperative opioid (promedol) and nonopioid (ketoprofen) consumption, the time to first rescue analgesia.

Results: There were no statistically significant differences between pectoral block and paravertebral block groups in intraoperative fentanyl consumption 2,2 (1,81-2,81) vs 1,9 $(1,63-2,25) \mathrm{mcg} / \mathrm{kg} / \mathrm{hour}(\mathrm{P}>0,05)$ and in the pain intensity during the first 24 hours after operation. The mean postoperative 24-hour promedol and ketoprofen consumption was $4,0( \pm 8,14) \mathrm{mg}$ vs $5,0( \pm 8,85) \mathrm{mg}(\mathrm{P}>0,05)$ and $66,7( \pm 66,09) \mathrm{mg}$ vs $95,8( \pm 90,78) \mathrm{mg}(\mathrm{P}>0,05)$ in the pectoral and paravertebral block groups respectively. Time to the first analgesia request was longer in pectoral block group - $540(455,0-600,0)$ min vs $515(265,0-650,0)$ min $(P>0,05)$. There were no complications after pectoral blocks and 2 complications after paravertebral blocks.
\end{abstract}

Conclusions: in breast cancer surgery pectoral nerve block type II can provide postoperative analgesia comparable to thoracic paravertebral block with lower complications rate.

KEY WORDS: thoracic paravertebral block, pectoral nerve block, breast surgery

Wiad Lek. 2020;73(7):1470-1475

\section{INTRODUCTION}

Breast cancer is the most frequently diagnosed malignancy among women in the regions with different economic development with an estimated 1.67 million new cancer cases diagnosed in 2012 [1]. In Ukraine these cancers are also the first most common malignancies among women. And in last decades its incidence has increased [2]. The main surgical method of treatment for operable breast cancer is organ-sparing surgery with lymph node dissection. Despite the variety of methods of analgesia, up to $40 \%$ of women suffer from acute pain after this surgery [3].There is a high risk of chronic pain development after this surgery [4].Therefore, research and development of safe analgesia techniques for these interventions remains a topic of interest.

Widespread use of the ultrasound visualization for the peripheral nerve blockade has given an impetus to the development of new, minimally invasive myofascial blocks. Particularly, in the last few years for the chest wall anesthesia has been proposed the erector spinae plane block, serratus anterior plane block, pectoral nerve block types I and II and transversus thoracic muscle plane block. All of them currently are considered as simple to perform, superficial and safe blocks, and have a small number of contraindications. However, during several decades for analgesia in the breast surgery more invasive techniques, in particular, thoracic epidural analgesia, paravertebral and intercostal nerve blocks, have been effectively used. Actually, the thoracic paravertebral block provides good perioperative analgesia [5], and it can be used even as monoanesthesia, when block is performing at multiple vertebral levels [6]. The main disadvantage of this method is the risk of serious complications, such as pneumothorax and administration of local anesthetic in the subarachnoid space. There is no clear answer to the question whether minimally invasive pectoral nerve block type II (Pecs block) can be as effective as thoracic paravertebral block (TPVB) for perioperative analgesia. Several studies show that pectoral nerve block reduces the need for opioid analgesics in the postoperative period compared with paravertebral block [7]. On the other hand, some studies have shown that TPVB has more powerful analgesic effect than Pecs block [8]. Versyck et al. performed the meta-analysis of five studies, which shows that analgesic effect of these two methods is comparable [9].

\section{THE AIM}

The aim to compare the efficacy of pectoral nerve block type II and thoracic paravertebral block for analgesia during and after breast cancer surgery. 


\section{MATERIALS AND METHODS}

The study was conducted from January 2018 to May 2019 in the Feofaniya Clinical Hospital - the clinical site of NMAPE's Department of Anesthesia and Intensive Care. The work plan was approved by the institutional ethics committees. Female patients in the age group of $18-80$ years with ASA grade I-II, who were undergoing elective mastectomy or quadrantectomy with axillary lymph node dissection, were included in this study. Also we used exclusion criteria, such as allergy to local anesthetics; a body mass index of more than $35 \mathrm{~kg} / \mathrm{m}^{2}$; pregnant women; patients with chronic pain in the arm and/or chest, who constantly use painkillers and/or other medications to treat chronic pain; patients who were previously operated on this mammary gland and/or received radiotherapy; patients who use anticoagulants or have a bleeding disorders; skin inflammation at the local anesthetic injection site.

Patients were randomized (1:1 ratio) into two groups: pectoral nerve block (Pec) and paravertebral block (TPVB). The perioperative procedures in both groups were similar and consistent with the Feofaniya Hospital's local protocols of preparation, examination and. After admission to the operating room, adequateintravenous access and standard monitoring including pulse oximetry, non-invasive blood pressure measurement, ECG, capnographyand BIS-monitoringwere established for the patient. After establishing a peripheral intravenous linediazepam $5 \mathrm{mg}$ and non-steroidal anti-inflammatory drug (ketoprofen $100 \mathrm{mg}$ ) were administered for premedication. Then appropriate block was performedin aseptic settings and under ultrasoundguidance.

Pectoral nerve block was performed with the technique described by Blanco et al. [10]. The ultrasound machine "General electric Logiq E" (GE Healthcare, Little Chalfont, United Kingdom) with a linear probe $(8-15 \mathrm{MH})$ was used to visualize the anatomical structures. Probe was placed in the subclavian area perpendicular to the middle of the clavicle, where we visualized the pectoral muscles (major and minor), subclavian artery and subclavian vein. Then we moved the probe toward the armpit and at the level of the fourth rib, after achieving the optimal ultrasound image, in the aseptic settings and after skin infiltration anesthesia with lidocaine $1 \%$, we injected ropivacaine $0.375 \% 20 \mathrm{ml}$ between the pectoralis minor and serratus anterior muscles, using in-plane technique and the needle Stimuplex D $50 \mathrm{~mm}$ (B. Braun Melsungen AG, Germany). Then, after pulling up the needle, ropivacaine $0.375 \% 10 \mathrm{ml}$ was injected into the space between the pectoralis major and minor muscles.

The paravertebral block was performed with the patient in the sitting position, at the level of 3-4 thoracic vertebra under ultrasound guidance. The linear probe of the ultrasound machine General electric Logiq E (GE Healthcare, Little Chalfont, United Kingdom) was placed parallel to the spinous processes, $2.5-3 \mathrm{~cm}$ from the midline in the direction of the affected side. Then, under all aseptic precautions and after skin infiltration anesthesia with lidocaine $1 \%$, using in-plane technique and the needle Stimuplex D $50 \mathrm{~mm}$ (B. Braun Melsungen AG, Germany), ropivacaine 0.5\% $20 \mathrm{ml}$ was slowly injected into the paravertebral space.
During and after performing the block, hemodynamic parameters (blood pressure, heart rate), respiration (capillary blood saturation, respiratory rate) and the patient's subjective sensations were monitored to control the intravascular administration of the local anesthetic or its system resorptive effects. The time for performing the blocks, including all aseptic precautions, was recorded. After the block's procedure, the loss of tactile sensitivity in the dermatomes from $\mathrm{T} 1$ to $\mathrm{T} 8$ and accordingly to the area of local anesthetic distribution was assessed by pin-pricking with a sterile needle every 5 minutes while the patient was conscious. General anesthesia was induced following 15-20 minutes with injection of fentanyl $1-2 \mathrm{mg} / \mathrm{kg}$ and propofol $2 \mathrm{mg} / \mathrm{kg}$. Airway patency was maintained by laryngeal mask. Total intravenous anesthesia was supported by continuous infusion of the propofol. BIS-monitoring values were maintained between 40 and 60 . Additional fentanyl $50 \mu \mathrm{g}$ IV boluses were administered when we observed patient's motor reactions, or when heart rate or systolic blood pressurehas increased for more than $20 \%$ from the baseline, or when BIS values indicated that patient requires deepening of anesthesia. After awakening patients were transported into the ward. Ketoprofen $100 \mathrm{mg}$ was administered for pain relief when pain intensity was greater than 3 points by the Numerical rating scale (NRS) or after the patient's request. If after the ketoprofen administration the pain intensity remained above 3 points or if patient subjectively was unsatisfying from this analgesia, then opioid analgesic (promedol $2 \% 20 \mathrm{mg}$ ) was administered intramuscular for pain relief.

During the operation, the total doses of fentanyl and propofol were noted. Postoperative pain was evaluated using a Numerical rating scale (NRS, $0-10$ points; $0=$ no pain and 10=worst imaginable pain) at rest at $0,1,2,6$, 12,18 and 24 hours after surgery (if the patient slept at the scheduled time, the assessment was not conducted). Also were noted the needs for ketoprofen and promedol and the time to the first administration of analgesics. Postoperative nausea and vomiting was evaluated using a four-point numerical scale ( $1=$ no nausea, $2=$ mild nausea, $3=$ single vomiting, $4=$ multiple vomiting). Also were noted the time of first meal and getting the patient out of bed. All possible block-related complications were recorded too.

The obtained data were entered into a Microsoft Excel 2007 spreadsheet (Microsoft Corporation, USA). Program "STATISTICA 10.0" (StatSoftInc., USA) was used for statistical analysis. The Shapiro-Wilk test was used to check the normality of quantitative data's distribution. In the study non-normally distributed quantitative data are presented as medians and interquartile intervals. Normally distributed quantitative data in the study are presented as means and squared deviation from the mean. The Mann-Whitney U test was used to determine the significance of the differences between groups (i.e., P-value). The categorical data are presented as numbers and percentages, and the significance of the differences between groups was calculated using the Pearson's chi-square test. P-value $<0.05$ was considered as statistically significant. 


\section{RESULTS AND DISCUSSION}

Sixty patients were enrolled in the study and randomized into two equal groups with no statistically significant differences in age, weight and duration of surgery. Quadrantectomy/mastectomy ratio was $14 / 16$ in the Pecs group and $13 / 17$ in the TPVB group (Table I).

The duration of the performing the pectoral nerve block was 14 (12-16) minutes, paravertebral block - 12 (10-15) minutes $(\mathrm{P}>0.05)$. Pectoral nerve block covered 5 (4.0-6.0) dermatomes, paravertebral - 3 (2.0-4.0) $(\mathrm{P}<0.05)$. Propofol doses were comparable in both groups: 5.6 (4.7-7.16) and $5.8(4.4-7.56) \mathrm{mg} / \mathrm{kg} / \mathrm{h}$, respectively $(\mathrm{P}>0.05)$. The intraoperative need for fentanyl was slightly less in the TPVB group - $1.9(1.63-2.55)$ versus $2.2(1.81-2.81) \mathrm{mcg} /$ $\mathrm{kg} / \mathrm{h}(\mathrm{P}>0.05)$.

The difference of pain intensity in the postoperative period, assessed with Numerical Rating Scale, was not statistically significant between two groups (Table II).

The number of patients, who did not require any analgesia after surgery, was 9 in the Pecs group and 10 in TPVB group $(\mathrm{P}>0.05)$. Although the need for analgesia with ketoprofen and promedol was lower and the time to first analgesic administration was longer in the Pecs group compared with TPVB group, but the differences were not statistically significant: $66.7( \pm 66.09)$ and $95.8( \pm 90.78) \mathrm{mg}$ $(\mathrm{P}>0.05), 4.0( \pm 8.14)$ and $5.0( \pm 8.85) \mathrm{mg}(\mathrm{P}>0.05), 540$ (455.0-600.0) and 515 (265.0-650.0) $\mathrm{min}(\mathrm{P}>0.05)$, respectively. Patients got out of bed and began drinking/ eating faster in the Pecs group than in the TPVB group: 150 (120.0-240.0) and 180 (120.0-240.0) $\min (\mathrm{P}>0.05)$, 165 (120.0-240.0) and 180 (120.0-240.0) $\min (\mathrm{P}>0.05)$, respectively. The rates and severity ( $\max$ score -3 points) of nausea were higher in the TPVB group: 5 vs 2 patients respectively $(\mathrm{P}>0.05)$ (Table III).

The block-related complications: in the postoperative period one patient from the TPVB group had signs of local anesthetic system toxicity effects including convulsions and lowering of consciousness, which passed quickly after appropriate treatment; also one patient had a significant blood pressure decreasing and required norepinephrine infusion during surgery and in the early postoperative period. There were no complications in the Pecs group.

The innervation of the thoracic wall and axilla region is quite complex and according to modern concepts is provided by several groups of nerves: 1) anterior and lateral skin branches of the 2-6 intercostal nerves and branches of the first and second intercostal nerves (n. intercostobrachialis) (Th1-6); 2) the nerves from the brachial plexus - the medial (C8-T1) and lateral (C5-C7) pectoral nerves, n. thoracodorsalis (C6-C8) and $n$. thoracicus longus (C5-C7); 3) supraclavicular branches of the cervical plexus (C3-C4).

In the study we compared the analgesic effects of two thoracic wall nerve blocks, as TPVB is well-researched and effective method and Pecs block may be no less effective, but currently has a smaller evidence base. In this study the paravertebral block was performed at only one Th 3-4 level, as well as in most previous researches, which compared the efficacy of these two techniques $[7,11,12,13]$. Although there is evidence that analgesic effect is better when the paravertebral block is performed at several levels [14].

The body's areas that are blocked by Pecs block and TPVB are slightly different. After administration into the paravertebral space at the Th3-Th4 level, local anesthetic spreads more in the caudal and less in the cranial directions [15], and blocks the intercostal nerves, their anterior and lateral skin branches respectively. In this case local anesthetic does not block the brachial plexus and supraclavicular nerves. Kulhari et al. reported that after single-shot administration $0.5 \%$ ropivacaine $25 \mathrm{ml}$ caused a sensory block for a median of three segments [12], and Cheema et al. reported that $0.5 \%$ bupivacaine $15 \mathrm{ml}$ blocked five segments [16]. In our study the median spread of anesthesia was also three segments for paravertebral block.

After performing the pectoral nerve block and the local anesthetic injection between the pectoralis major and minor muscles and between the pectoralis minor and serratus anterior muscles, we can expect the block of four-six lateral cutaneous branches of the intercostal nerves and four nerves from the brachial plexus (n. thoracodorsalis, n. thoracicus longus, nn. pectoralis lateralis and medialis). An additional important factor is that local anesthetic moves into the axillary fossa, provides an analgesia of the axillary lymph node dissection area and blocks nn. intercostobrachialiss (T1-T2). This block does not anesthetize the region of supraclavicular nerves and intercostal's nerves anterior skin branches innervation. Blanco et al. described that pectoral nerve block anesthetized four segments, which sometimes varied up to six segments [10]. Kulhari et al. reported that after the injection of $15 \mathrm{ml}$ of anesthetic the sensor block reached 4 segments [12]. In our study the median spread of anesthesia was 5 segments, which may be due to the local anesthetic administration as much as possible caudally over the fourth rib; also we used larger volume of local anesthetic $(20 \mathrm{ml})$ than Kulhari et al.

The type of the anesthetic spread is related with the blocks' analgesic efficacy. In the paravertebral block group patients did not have an adequate analgesia in the axillary region, thus they required more opioid analgesics during and after major surgeries such as mastectomy. On the other hand, pectoral nerve block provided effective analgesia for axillary lymph node dissection and adequately anesthetized the lateral part of the mammary gland, but it did not work when the surgeons performed incision more medially and not always worked when incision involved the lower dermatomes.

El-Sheikh et al. and Wahba et al. reported about the statistically significant decreasing of the intraoperative need for fentanyl after the Pecs block compared with paravertebral block $[11,7]$. At the same time, based on the meta-analysis of seven studies, which was performed by Versyck et al., the intraoperative need for opioids was the similar after Pecs block compared to the total anesthesia without any regional techniques [9]. In our study slightly less need for fentanyl during surgery was observed in the paravertebral block group - $1.9(1.63-2.55) \mathrm{mcg} / \mathrm{kg} / \mathrm{h}$ compared to the Pecs block - $2.23(1.81-2.81) \mathrm{mcg} / \mathrm{kg} / \mathrm{h}$, but this difference 
Table I. Demographic data and operative data.

\begin{tabular}{cccc}
\hline & Pecs group & TPVB group & P-value \\
\hline $\mathrm{n}$ & 30 & 30 & \\
\hline Age & $60,5(47,0-67,0)$ & $57,0(45,0-62,0)$ & 0,1973 \\
\hline Weight & $74,0(64,0-83,0)$ & $74,0(62,0-86,0)$ & 0,8858 \\
\hline ASA I/II & $14 / 16$ & $13 / 17$ & 0,7952 \\
\hline Dustectomy/quadrantectomy & $11 / 19$ & $9 / 21$ & 0,5839 \\
\hline
\end{tabular}

Continuous data are presented as median (interquartile range). Categorical variables are presented as number. ASA = American Society of Anesthesiologists.

Table II. Postoperative pain scores (Numerical rating scale).

\begin{tabular}{cccc}
\hline & Pecs group & TPVB group & P-value \\
\hline NRS 0 & $1(0-1)$ & $0(0-1)$ & 0,2249 \\
\hline NRS 1 & $1(1-2)$ & $1(1-1)$ & 0,1874 \\
\hline NRS 2 & $1,5(1-3)$ & $1(1-2)$ & 0,4021 \\
\hline NRS 6 & $1,5(1-3)$ & $2(1-3)$ & 0,6367 \\
\hline NRS 12 & $2(1-3)$ & $2(1-3,5)$ & 0,8615 \\
\hline NRS 18 & $1,5(1-3)$ & $2(1-2)$ & 0,4933 \\
\hline NRS 24 & $2(1-2,5)$ & $2(1-2)$ & 0,9618 \\
\hline
\end{tabular}

Data are expressed as the median (interquartile range)

Table III. Postoperative analgesic consumption, duration of the block procedure, dermatomal spread, rate of nausea.

\begin{tabular}{cccc}
\hline & Pecs group & TPVB group & P-value \\
\hline Duration of the block procedure, $\min$ & $14,0(12,0-16,0)$ & $12,0(10.0-15,0)$ & 0,1523 \\
\hline Number of involved dermatomes & $5,0(4,0-6,0)$ & $3,0(2,0-4,0)$ & 0,0044 \\
\hline Propofol, $\mathrm{mg} / \mathrm{kg} / \mathrm{h}$ & $5,62(4,73-7,16)$ & $5,81(4,39-7,56)$ & 0,7910 \\
\hline Fentanyl, $\mathrm{mcg} / \mathrm{kg} / \mathrm{h}$ & $2,2(1,81-2,81)$ & $1,9(1,63-2,25)$ & 0,2956 \\
\hline Promedol, $\mathrm{mg}$ & $4,0( \pm 8,14)$ & $5,0( \pm 8,85)$ & 0,6723 \\
\hline Ketoprofen, $\mathrm{mg}$ & $66,7( \pm 66,09)$ & $95,8( \pm 90,78)$ & 0,2792 \\
\hline Without analgesia & $9 / 30(30 \%)$ & $10 / 30(33 \%)$ & 0,7932 \\
\hline Time to first analgesia, min & $540(455,0-600,0)$ & $515(265,0-650,0)$ & 0,6773 \\
\hline Time to patient's activization & $150(120,0-240,0)$ & $180(120,0-240,0)$ & 0,5865 \\
\hline Time to first meal, min & $165(90,0-240,0)$ & $180(120,0-240,0)$ & 0,5919 \\
\hline Chi-square test & $28 / 2 / 0 / 0$ & $25 / 3 / 2 / 0$ & 0,2291 \\
\hline
\end{tabular}

Continuous data are expressed as the median (interquartile range) or as mean ( \pm squared deviation). Categorical variables are presented as number (percents).

was not statistically significant. The propofol doses were similar in both groups (Pecs/TPVB): $5.6(4.7-7.16)$ and $5.8(4.4-7.56) \mathrm{mg} / \mathrm{kg} / \mathrm{h}$ respectively and were close to the sedative doses.

The pain intensity at rest, assessed using a NRS, was comparable in both groups during the first 24 hours after surgery (Table II). Heterogeneous data about pain intensity were obtained in previous studies. Syal et al. obtained results with significantly higher scores of the pain intensity in the pectoral nerve block group, but it should be noted that in this study they injected for block only $20 \mathrm{ml}$ of local anesthetic instead of $30 \mathrm{ml}[8]$. Kulhari et al. reported the same pain intensity in both groups [12]. Wahba et al. in their study observed the lower NRS scores during the first 12 hours after surgery in the pectoral nerve block group, but during the period from 12 to 24 hours the results were conversely. In general, we can note that in our study the pain intensity was lower than in similar ones, which may be related to the women's ethnic and cultural characteristics in our region.

Breast cancer surgery is not associated with a severe postoperative pain syndrome. Gerbershagen et al. in their study have compared the pain intensity during the first day after 179 types of surgery intervention. Breast cancer surgeries, such as mastectomy and quadrantectomy with axillary lymph node dissection, were at 146 and 160 places 
[17]. In our study 9 women in the Pecs group (30\%) and 10 women in the TPVB (33\%) did not require any analgesia during the whole postoperative period. But comparing the groups, the need for opioid and non-opioid analgesics in the postoperative period was less in the Pecs group, although without a statistically significant difference. In the most currently available studies the postoperative need for opioids (patient-controlled morphine analgesia) was higher in the TPVB group, with statistical significance in two studies $[7,12]$ and without statistical significance in another one [11]. In only one study of Syal et al., which compared fentanyl analgesia in the postoperative period, there was a greater need of opioids in Pecs group, but without statistical significance [8].

The time to first rescue analgesia was longer in the Pecs group and the same results were also observed in other similar studies $[7,12,11,13]$. In previous studies the time after surgery to the first rescue analgesia varied due to the different plans of postoperative analgesia according to the study design. In our study we evaluated the time to first administration either opioid or non-opioid analgesics.

The rate and intensity of postoperative nausea was higher in the TPVB group, but without statistical significance. There were two patients with nausea (assessed as 2 points) in the Pecs group, and five patients in the TPVB group (two of them had 3-points nausea). Patients in the Pecs group had earlier started getting out of bed and eating, but these findings also were not statistically significant.

As well as in previous studies $[7,12,11,8]$, no complications were observed after pectoral nerve blocks. Instead, in the TPVB group two patients had block-related complications. One patient experienced a system resorptive effect of local anesthetic, although we did not exceed the recommended safe doses for ropivacaine. The convulsions occurred after patient awakening during transportation from the operating room, and were successfully treated by administration of diazepam $10 \mathrm{mg}$. Then this patient was under observation until the next day morning and she had not any health-related problems. Another patient had hypotension, which occurred after 15 min since the block performing, at the beginning of the general anesthesia induction and required correction with small doses of norepinephrine during the surgery and during the first two hours after intervention. Tahiri et al. in their meta-analysis reported that hypotension and bradycardia are the most common complications of the paravertebral block in breast surgery, and the overall rate of complications, including pneumothorax and epidural local anesthetic spreading, reaches up to $12 \%$ [18]. In our study complications rate was $6.7 \%$. Thus the safety profile of the pectoral nerve block type II is better than safety profile of the thoracic paravertebral.

\section{CONCLUSIONS}

Pectoral nerve block type II provides a comparable to single-level thoracic paravertebral block analgesia efficacy during and after breast cancer surgery, and has a lower complications rate. These results allow consider this block as a good alternative to TPVB. Further larger studies are required to confirm these findings by reaching statistically significant evidences and to investigate the Pecs II effects on the chronic pain development during the long-term period.

\section{REFERENCES}

1. Ferlay J., Soerjomataram I., Dikshit R. et al. Cancer incidence and mortality worldwide: Sources, methods and major patterns in GLOBOCAN 2012. International Journal of Cancer. 2015;136(5):359-86.

2. Biuleten Natsionalnoho kantser-reiestru v Ukraini №20. Kyiv, 2019. Available from: http://www.ncru.inf.ua/publications/BULL_20/ PDF_E/42-43-mol.pdf [reviewed: 2019.11.08.].

3. Poleshuck E.L., Katz J., Andrus C.H. et al. Risk factors for chronic pain following breast cancer surgery: a prospective study. J Pain. 2006;7:626-634.

4. Rawal N. Current issues in postoperative pain management. Eur J Anaesthesiol. 2016:33:160-171.

5. Wu J., Buggy D., Fleischmann E. et al. Thoracic paravertebral regional anesthesia improves analgesia after breast cancer surgery: a randomized controlled multicentre clinical trial. Canadian Journal of Anaesthesia. 2015;62(3):241-251.

6. Das S., Bhattacharya P., Mandal M.C. et al. Multiple-injection thoracic paravertebral block as an alternative to general anaesthesia for elective breast surgeries: A randomised controlled trial. Indian J Anaesth 2012;56(1):27-33.

7. Wahba S.S., Kamal S.M. Thoracic paravertebral block versus pectoral nerve block for analgesia after breast surgery. Egyptian Journal of Anaesthesia. 2014;30:129-135.

8. Syal K., Chandel A. Comparison of the post-operative analgesic effect of paravertebral block, pectoral nerve block and local infiltration in patients undergoing modified radical mastectomy: A randomised double-blind trial. Indian J Anaesth. 2017;61(8):643-648.

9. Versyck B., van Geffen G.J., Chin K.J. Analgesic efficacy of the Pecs II block: a systematic review and meta-analysis. Anaesthesia. 2019;74(5):663-673.

10. Blanco R., Fajardo M., Parras M.T. Ultrasound description of Pecs II (modified Pecs I): a novel approach to breast surgery. Rev Esp Anestesiol Reanim. 2012;59:470-475.

11. El-Sheikh S.M., Fouad A., Bashandy G.N. et al. Ultrasound guided modified pectoral nerves block versus thoracic paravertebral block for perioperative analgesia in major breast surgery. Medical Journal of Cairo University 2016;84:189-95.

12. Kulhari S., Bharti N., Bala I. et al. Efficacy of pectoral nerve block versus thoracic paravertebral block for postoperative analgesia after radical mastectomy: a randomized controlled trial. British Journal of Anaesthesia. 2016;117:382-6.

13. Annamalai G., Durairaj A.K., Kailasam K.R. Pectoral nerve block versus thoracic paravertebral block - Comparison of analgesic efficacy for postoperative pain relief in modified radical mastectomy surgeries. Journal of Evolution of Medical and Dental Sciences 2017;6:4412-16.

14. Kasimahanti R., Arora S., Bhatia N. et al. Ultrasound-guided single- vs double-level thoracic paravertebral block for postoperative analgesia in total mastectomy with axillary clearance. J Clin Anesth. 2016;33:414-21.

15. Marhofer D., Marhofer P., Kettner S.C. et al. Magnetic Resonance Imaging Analysis of the Spread of Local Anesthetic Solution after Ultrasoundguided Lateral Thoracic Paravertebral Blockade 2013;118(5):1106-12.

16. Cheema S.P.S., Ilsley D., Richardson J. et al. A thermographic study of paravertebral analgesia. Anaesthesia1995;50:118-21. 
17. Gerbershagen H.J., Aduckathil S., van Wijck A.J. et al. Pain intensity on the first day after surgery: a prospective cohort study comparing 179 surgical procedures. Anesthesiology. 2013;118(4):934-44.

18. TahiriY., Tran D.Q., Bouteaud J. et al. General anaesthesia versus thoracic paravertebral block for breast surgery: a meta-analysis. J Plast Reconstr Aesthet Surg. 2011;64(10):1261-9.

\section{ORCID and contributionship:}

Volodymyr V. Martsiniv: 0000-0002-3706-5284 ${ }^{A, B, D}$

Oleg A. Loskutov: 0000-0002-7646-9193 ${ }^{A, F}$

Andriy M. Strokan: 0000-0002-5415-6065 ${ }^{B, D}$

Mihaylo V. Bondar: 0000-0003-2657-4654 C,E

\section{Conflict of interest:}

The Authors declare no conflict of interest.

\section{CORRESPONDING AUTHOR}

Volodymyr V. Martsiniv

Feofaniya Clinical Hospital of State Management of Affairs

21 Akademika Zabolotnogo st., 03143 Kyiv, Ukraine

tel: +380664994519

e-mail:vovamart@yahoo.com

Received: 15.08 .2019

Accepted: 21.04 .2020

A - Work concept and design, B - Data collection and analysis, C - Responsibility for statistical analysis,

D-Writing the article, $\mathbf{E}$-Critical review, $\mathbf{F}$ - Final approval of the article 